\title{
The types, incidence and demographic distribution of benign oral and maxillofacial neoplasms among patients attending Muhimbili National Hospital in Tanzania, 2008-2013
}

\author{
JEREMIAH R. MOSHY ${ }^{1}$ and KARPAL S. SOHAL ${ }^{2 *}$ \\ ${ }^{1}$ Muhimbili University of Health and Allied Sciences, Department of Oral and Maxillofacial Surgery, P.0. Box 65001, \\ Dar es Salaam Tanzania \\ ${ }^{2}$ Muhimbili National Hospital, Department of Oral and Maxillofacial Surgery, P.O. Box 65014, Dar es Salaam Tanzania
}

\begin{abstract}
Background: Pathological processes of oral and maxillofacial region are generally classified as benign or malignant based on specific histological criteria, including the presence or absence of necrosis, mitotic figures as well as basic understanding of the entity. The objective of this study was to determine the types, prevalence and demographic distribution of benign oral and maxillofacial tumours among patients treated at Muhimbili National Hospital in Tanzania.

Methods: In this retrospective study, data on histological results of lesions of the oral and maxillofacial region were retrieved from the archives at the Department of Oral and Maxillofacial Surgery of Muhimbili National Hospital were analysed. The tumour type, age, sex, file number and histopathological diagnosis of the patient were recorded. The study covered a period of from January 2008 to December 2013. The top ten lesions with higher frequency of occurrence from January to were picked for analysis.

Results: A total of 897 (males $=388$; females $=509$ ) histological results of patients with benign oral and maxillofacial lesions were obtained during the period under review. The age ranged from 0 to 88 years, mean age being $32.63 \pm 17.1$ while the age group of $20-29$ and $30-39$ were the most affected. A total of 136 different types of benign lesions were reported and ameloblastoma was the most common benign lesion (27.4\%) followed by ossifying fibroma (18.7\%), pyogenic granuloma (11.4\%), pleomorphic adenoma (10.0\%), and fibrous dysplasia (9.6\%). Females were more affected than males, with a male to female ratio of 1:1.4 however the difference was statistically insignificant $(p=0.055)$.

Conclusion: Ameloblastoma and ossifying fibroma were the most common oral and maxillo-facia neoplasms at Muhimbili National Hospital. The young age groups were the most affected by these lesions.

Keywords: Benign, Oral, maxillofacial, neoplasm, Tanzania
\end{abstract}

\section{Introduction}

Pathological processes of oral and maxillofacial region are generally classified as benign or malignant, based on specific histological criteria, including the presence or absence of necrosis, mitotic figures as well as basic understanding of the entity. Orofacial tumours are known to exhibit geographical variation in prevalence and pattern due to cultural, social, occupational or climatic factors (Sankaranarayana, 1990; Krutchkoff, 1990; Arotiba et al., 2003; Aregbesola et al., 2005; Mohammed et al., 2010; Abdulai et al., 2012;). Wakiaga et al. (1997), in a report from Kenya, found ameloblastoma, Burkitt's lymphoma, ossifying fibroma and osteogenic sarcoma as the most common tumours in that order. Arotiba et al. (2003), found the orofacial tumours constituting $20.2 \%$ of patients seen over a period of 18 years in a study in Nigeria. The authors found squamous cell carcinoma and ameloblastoma as the most predominant orofacial tumours. In a study in Muhimbili (Tanzania) and Mulago Hospital (Uganda), Kamulegeya et al. (2008), found a high prevalence of malignant conditions compared to benign conditions.

Reports from different parts of the world show differences in the pattern of oral and maxillofacial tumours (Chidzonga et al.,1996; Tay,1999; Aregbesola et al., 2005; Jones et al., 2006).

\footnotetext{
${ }^{*}$ Correspondence: karpal@live.com
} 
Although some studies have been reported on oral and maxillofacial neoplasm in Tanzania, most were done years back and numbers reported were few (Kamulegeya et al., 2008). It is therefore important that an update on different histopathological entities reported and recorded at the oral and maxillofacial centers in Tanzania is document. The objective of this study was to determine the types, incidence and demographic distribution of benign oral and maxillofacial tumours among patients treated at Muhimbili National Hospital in Tanzania.

\section{Material and Methods}

\section{Study site and data collection}

This was a retrospective study where by histological results of lesions that occurred in oral and maxillofacial region from 1st January 2008 to 31st December 2013 were retrieved from the archives at the Department of Oral and Maxillofacial Surgery at Muhimbili National Hospital (MNH) in Dar es Salaam, Tanzania. MNH is the national referral and teaching hospital with 1,500 bed facility attending about 1,000-1,200 outpatients and inpatients per week (http://www.mnh.or.tz/index.php/).

The tumour type, age, sex, file number and histopathological number of the patient were recorded. Diagnosis was recorded as reported in the biopsy result slip. Reports of fine needle aspiration cytology were excluded. Those reports which had no final diagnosis were excluded as well. In case where a single patient had more than one result, as one for pre-surgery incisional biopsy and another of post-surgical excision of the lesion, the post-op results were included. The histological result slip which had malignant lesions as final diagnoses, were excluded as well. The top ten lesions with higher frequency of occurrence were picked for analysis.

\section{Data analysis}

The data for histological diagnosis and demographic data were entered into a dataset and data analysis was done by Statistical Package for Social sciences (SPSS) computer program version 19.

\section{Ethical consideration}

Permission to conduct this study was sought from and granted by Muhimbili National Hospital.

\section{Results}

A total of 897 histological results of patients with benign oral and maxillofacial lesions were obtained from the archives of histological results from 2008 to 2013. Of these histological results, 509 (56.7\%) were of female patients and $388(43.2 \%)$ of male patients. The mean age was $32.63 \pm 17.1$ years (range= $0-88$ years). Analysis of the top 10 lesions with highest frequency of occurrence showed that the age group of 20-29 and 30-39 were the most affected (Table 1).

Table 1: Distribution of top 10 conditions according to age group

\begin{tabular}{lllllllllll}
\hline Condition & \multicolumn{3}{l}{ Age group (in years) } & \multicolumn{3}{c}{ Mean age } \\
& $0-9$ & $10-19$ & $20-29$ & $30-39$ & $40-49$ & $50-59$ & $60-69$ & $70+$ & \\
\hline Ameloblastoma & 5 & 37 & 42 & 41 & 16 & 13 & 4 & 5 & 31.5 \\
Ossifying fibroma & 3 & 24 & 26 & 22 & 19 & 11 & 4 & 2 & 33.19 \\
Pyogenic granuloma & 4 & 4 & 15 & 14 & 11 & 12 & 4 & 4 & 38.47 \\
Pleomorphic adenoma & 1 & 6 & 19 & 11 & 10 & 4 & 5 & 4 & 36.72 \\
Fibrous dysplasia & - & 19 & 14 & 14 & 7 & 3 & - & - & 27.84 \\
Inflammatory process & 1 & 8 & 7 & 8 & 9 & 6 & 7 & 1 & 37.48 \\
Dentigerous cyst & - & 13 & 10 & 7 & 4 & 2 & - & - & 27.81 \\
Haemangioma & 3 & 3 & 6 & 2 & 2 & 3 & 1 & 3 &
\end{tabular}


Ameloblastoma was the most common benign lesion, accounting for $27.4 \%(n=163)$ of all benign lesions followed by ossifying fibroma 111 (18.7\%), and pyogenic granuloma 68 (11.4\%). Others were pleomorphic adenoma (10.0\%), and Fibrous dysplasia (9.6) (Table 2).

Table 2: Distribution of the 10 most common benign maxillofacial neoplasms

\begin{tabular}{lcc}
\hline Condition & Frequency & Percentage (\%) \\
\hline Ameloblastoma & 163 & 27.4 \\
Ossifying fibroma & 111 & 18.7 \\
Pyogenic granuloma & 68 & 11.4 \\
Pleomorphic adenoma & 60 & 10.0 \\
Fibrous dysplasia & 57 & 9.6 \\
Inflammatory process & 46 & 7.7 \\
Dentigerous cyst & 37 & 6.3 \\
Hemangioma & 21 & 3.5 \\
Epulis & 17 & 2.9 \\
Odontogenic Myxoma & 15 & 2.5 \\
Total & 595 & $\mathbf{1 0 0}$ \\
\hline
\end{tabular}

Majority of the neoplasms had predominant female distribution except for hemangioma and Dentigerous cyst, where male dominance was observed (Table 3). The overall male to female ratio for the top 10 benign lesion was found to be 1:1.4. The difference in occurrence of the neoplasms between males and females was however statistically insignificant $(p=0.055)$.

Table 3: Distribution of top 10 conditions by sex

\begin{tabular}{lccc}
\hline Condition & Male & Female & Male to Female Ratio \\
\hline Ameloblastoma & 76 & 87 & $1: 1.1$ \\
Ossifying fibroma & 44 & 67 & $1: 1.5$ \\
Pyogenic granuloma & 26 & 42 & $1: 1.6$ \\
Pleomorphic adenoma & 20 & 40 & $1: 2$ \\
Fibrous dysplasia & 19 & 38 & $1: 2$ \\
Inflammatory process & 18 & 28 & $1: 1.6$ \\
Dentigerous cyst & 21 & 16 & $1: 0.8$ \\
Hemangioma & 12 & 9 & $1: 0.8$ \\
Epulis & 9 & 8 & $1: 0.9$ \\
Odontogenic Myxoma & 1 & 14 & $1: 14$ \\
Total & 246 & 349 & $\mathbf{1 : 1 . 4}$ \\
\hline
\end{tabular}

\section{Discussion}

Orofacial tumours are known to exhibit geographical variation in prevalence and pattern due to cultural, social, occupational or climatic factors (Sankaranarayana, 1990; Krutchkoff, 1990; Arotiba et al., 2003; Aregbesola et al., 2005; Mohamed et al., 2010; Abdulai et al., 2012). Some of the lesions are observed in a particular age group and are more prevalent in one sex than the other (Kamulegeya et al., 2008). The current study found no statistical difference in incidence of benign orofacial tumours 
between males and females. The age group of 20 to 39 years, was the most affected by these tumours. Despite being dealing with benign maxillofacial neoplasms and with different methodological settings; the male to female ration of 1:1.3 in this study contrasts with the 1:1 to 2.3:1 reported by Lilly-Tariah et al. (2009) in Nigeria. In addition, the observed sex ratio in the present study differs from the 1.7:1 reported by Abuidris et al. (2008) in central Sudan. These studies indicate higher occurrence in male contrary to the findings of our current study which supports a female preponderance. This is probably because of difference in health seeking behaviour between males and females, with latter tending to show more concern about their health and appearance hence are more likely to health care earlier (Galdas et al., 2005; Kaur et al., 2013).

The higher occurrence of benign oral and maxillofacial neoplasms in the age group 20 to 39 years concurs with findings by Odukoyo (1995). During this age, there is active development of diverse pathological lesions. Also multiple foci of embryonic tissue (ectodermal and neuroectodermalmesodermal in origin are contained within the jaws during the first 25 years of life (Hoffman, 1997; Butt et al., 2007).

Findings or our study also indicate that ameloblastoma, ossifying fibroma, pyogenic granuloma and fibrous dysplasia are the commonest neoplasms. The findings are comparable with other reports (Salvin et al., 1969; Aregbesola et al., 2005; Bassey et al., 2014). One reason for relatively high frequency of occurrence is the heterogeneous epithelial origin of ameloblastoma (Tajima et al., 1992; Mendenhall et al., 2007). Also its persistent local growth in the maxillofacial area and its ability to produce marked deformity before leading to serious debilitation probably accounts for its early recognition and numerous subsequent reports.

The slow growth of ossifying fibroma may ultimately produce expansion and thinning of cortical plates of the maxilla and mandible, although perforation and mucosal ulceration are rare (Garg et al., 2014). Fibrous dysplasia has the slowly progressive enlargement of the affected jaw that is usually painless and typically presents as unilateral swelling, as lesion grows; facial asymmetry becomes evident and may be initial presenting complaint that will trigger the patient to seek for medical attention. Pyogenic granuloma is a tumour of granulation tissue. It is uncommonly seen elsewhere in the oral cavity, however may appear in the areas of frequent trauma, such as the lower lip, the buccal mucosa, and the tongue (Vaiyapuri et al., 2012). This lesion presents an over exuberant connective tissue reaction to stimuli or injury. They may be very large in size and can easily bleed causing discomfort to the patient compelling them to seek for medical attention.

In conclusion, the results of the current study reflect incidence of benign oral and maxillofacial tumours/conditions at Muhimbili National Hospital rather than prevalence in general population. Ameloblastoma was found to be the most common benign lesion affecting more of young age group and females. The pattern of occurrence of benign oral and maxillofacial tumours in this study will be of interest to the pathologists, oral and maxillofacial surgeons, and general dental practitioners as it roughly shades light to the trend of benign maxillofacial lesion in Tanzania.

\section{References}

Abdulai, A.E., Nwamah, I.K. \& Gyasi, R. (2012) Head and neck tumours in Ghanaian children. A 20-year review. International Journal of Oral and Maxillofacial Surgery 41, 1378-1382.

Abuidris, D.O., Elhaj, A.H., Eltayeb, E.A., Elgayli, E.M., Mustafa, O.M. (2008) Pattern of head and neck malignancies in Central Sudan-(study of 314 cases). Sudan Journal of Medical Sciences3, 105-108.

Aregbesola, S.B., Mgboko, V.I., Akinwande, J.A., Arole, G.F. \& Fadage, O.O. (2005) Orofacial tumours in suburban Nigerian children and adolescents. British Journal of Oral \& Maxillofacial Surgery 43, 226-231. 
Arotiba, J.T., Adebola, R.A., Ajike, S.O., Adeola, D.S., Ladeinde, A. (2003) Orofacial tumours and tumour like lesions in Kano, Nigeria. Nigerian Journal of Surgical Research 5, 134-139.

Bassey, G.O., Osunde, O.D. \& Anyanechi, C.E. (2014) Maxillofacial tumors and tumor-like lesions in a Nigerian teaching hospital: an eleven-year retrospective analysis. African Health Sciences14, 5663.

Butt, F.M.A., Chindia, M.L., Wakoli, K.A. (2007) Problem in diagnosing odontogenic myxoma. East African Medical Journal 84, 141-45.

Chidzonga, M.M., Lopez, V.M., Partha Alvarez, A.L. (1996) Orofacial biopsies a survey of 1732 cases seen over 10 years period. Central African Journal of Medicine 42, 102-108.

Galdas, P.M., Cheater, F. \& Marshall, P. (2005) Men and health help-seeking behaviour: literature review. Journal of Advanced Nursing 49, 616-623.

Garg, S., Sunil, M.K., Trivedi, A., Singh, P., Singla, N. \& Kaur, B. (2014) Osteodystrophic lesions of the jaws - a review. National Journal of Maxillofacial Surgery 5(2): 14- 24

Hoffman, S. \& Sheiham, A. (1977) Intraosseous and pasrosteal tumors of the jaws: 2nd Series 02-04

Jones, A.V. \& Franklin, C.D. (2006) An analysis of oral and maxillofacial pathology found in adult over a 30 year period. Journal of Oral Pathology \& Medicine 35, 392-401.

Kamulegeya, A. \& Kalyanyama, B.M. (2008) Oral maxillofacial neoplasms in an east African population; a 10-year retrospective study of 1863 cases using histopathological reports. BMC Oral health 8: 19

Kaur, M., Sodhi, S.K., Kaur, P., Singh, J. \& Kumar, R. (2013) Gender differences in health care seeking behaviour of Tuberculosis patients in Chandigarh. Indian Journal of Tuberculosis 60, 217-222.

Krutchkoff, D.J., Chen, J., Eissenberg, E. \& Katz, R.V. (1990) Oral cancer: a survey of 566 cases from the university of Connecticut oral pathology biopsy service 1975-1986. Oral Surgery, Oral Medicine and Oral Pathology 70, 192-198.

Lilly-Tariah, O.B., Somefun, A.O. \& Adeyemo, W.L. (2009) Current evidence on the burden of head and neck cancers in Nigeria. Head and Neck Oncology 1:1-14.

Mendenhall, W.M., Werning, J.W., Fernandes, R., Malyapa, R.S., Mendenhall, N.P. (2007) Ameloblastoma. American Journal of Clinical Oncology 30, 645-648.

Mohammed, A., Singh, A.S., Raubenheimer, E.J. \& Bouckaert, M.M.R. (2010) Adenomatoid Odontogenic tumour-review of literature and an analysis of 33 cases from South Africa. International Journal of Oral Maxillofacial Surgery 39, 843-846.

Odukoyo, O. (1995) Odontogenic tumours: analysis of 289 Nigerian cases. Journal of Oral Pathology \& Medicine 24, 454-457.

Salvin, G. \& Cameron, H.M. (1969) Ameloblastoma in African from Tanzania and Uganda. British Journal of Cancer 23, 31-38.

Sankaranarayan, R. (1990) Oral cancer in India: an epidemiological and clinical review. Oral Surgery, Oral Medicine \& Oral Pathology 69, 325-330.

Tajima, Y., Yokose, S., Sakamoto, E., Yamatoto, Y. \& Utsumi, N. (1992) Ameloblastoma arising in calcifying odontogenic cyst. Report of a case. Oral Surgery, Oral Medicine \& Oral Pathology 74, 776-779.

Tay, A.B.G. (1999) A 5 year survey of oral biopsies in an oral surgical unit Singapore: 1993-1997. Annals of Academy of Medicine, Singapore 28, 665-671.

Wakiaga, J.M., Onyango, J.F. \& Awange, D.O. (1997) Clinico-pathological analysis of jaw tumours and tumour like conditions at the Kenyatta National Hospital. East African Medical Journal 74, 6568. 